\title{
BMJ Open Receiving a prenatal diagnosis of Down syndrome by phone: a qualitative study of the experiences of pregnant couples
}

\author{
Stina Lou, ${ }^{\oplus 1,2}$ Kathrine Carstensen, ${ }^{1}$ Ida Vogel, ${ }^{2,3}$ Lone Hvidman, ${ }^{4}$ \\ Camilla Palmhøj Nielsen, ${ }^{1}$ Maja Lanther, ${ }^{1}$ Olav Bjørn Petersen ${ }^{2,4}$
}

To cite: Lou S, Carstensen K, Vogel I, et al. Receiving a prenatal diagnosis of Down syndrome by phone: a qualitative study of the experiences of pregnant couples. BMJ Open 2019;9:e026825. doi:10.1136/ bmjopen-2018-026825

- Prepublication history and additional material for this paper are available online. To view these files, please visit the journal online (http://dx.doi org/10.1136/bmjopen-2018026825).

Received 20 September 2018 Revised 8 January 2019 Accepted 1 February 2019

Check for updates

C Author(s) (or their employer(s)) 2019. Re-use permitted under CC BY-NC. No commercial re-use. See rights and permissions. Published by BMJ.

${ }^{1}$ Central Denmark Region, DEFACTUM - Public Health and Quality Improvement, Aarhus N, Denmark

${ }^{2}$ Center for Fetal Diagnostics, Aarhus University Hospital, Aarhus, Denmark

${ }^{3}$ Department of Clinical Genetics, Aarhus Universitetshospital, Aarhus, Denmark

${ }^{4}$ Department of Obstetrics and Gynecology, Aarhus Universitetshospital, Aarhus, Denmark

Correspondence to

Ms Stina Lou; stina.Iou@rm.dk

\section{ABSTRACT}

Objectives To examine how pregnant couples experience receiving a prenatal diagnosis of Down syndrome (DS) by phone-a practice that has been routine care in the Central Denmark Region for years.

Design Qualitative interview study.

Setting Participants were recruited from hospitals in Central Denmark Region, Denmark.

Participants Couples who had received a prenatal diagnosis of DS by phone and decided to terminate the pregnancy. They were recruited from the obstetric department where the termination was undertaken. During the study period (February 2016 to July 2017), 21 semistructured, audio-recorded interviews were conducted by an experienced anthropologist. Interviews were conducted 4-22 weeks after the diagnosis and analysed using thematic analysis.

Results A prearranged phone call was considered an acceptable practice. However, the first theme 'Expected but unexpected' shows how the call often came earlier than expected. Consequently, most women were not with their partner and were thus initially alone with their grief and furthermore responsible for informing their partner, which some considered difficult. The second theme 'Now what?' shows how during the phone calls, physicians were quick to enquire about the couples' agendas. As the majority had already decided to seek termination of pregnancy, the dialogue focused on related questions and arrangements. Only half of the couples received additional counselling.

Conclusion A prearranged phone call was considered an acceptable and appropriate practice. However, some aspects of this practice (particularly related to the context of the call) showed to be less than optimal for the couples. To make sure that a diagnostic result is delivered in accordance with the couples' needs and requests, the context of the call could be addressed and agreed on in advance by physicians and couples.

\section{INTRODUCTION}

Delivering information about a prenatal diagnosis is integral in fetal medicine. Physicians communicate diagnoses and abnormal results to pregnant women and couples countless times during their professional careers, ${ }^{12}$ whereas for the pregnant couples, it is an unparalleled experience that

\section{Strengths and limitations of this study}

- All interviewed couples had recent experience of receiving a prenatal Down Syndrome diagnosis by phone.

- All interviews were conducted by an experienced anthropologist.

- Researcher triangulation throughout the study supported a critical and reflexive analysis.

- The study does not include the experiences of couples who chose to continue the pregnancy.

- Patients were not directly involved in the development of the study design or the data analysis.

may drastically alter their future hopes and plans. $^{3-5}$

Several studies have shown how the manner in which the difficult news is delivered is essential for the understanding, coping and satisfaction of patients. ${ }^{6-8}$ Studies have also shown how training may improve health professionals' knowledge, communication skill and confidence in delivering difficult news, for example, in the newborn setting. ${ }^{9}{ }^{10}$ Furthermore, in order to support good and timely communication of difficult news, various protocols for good delivery of diagnoses and abnormal results have been developed to support a patient-centred approach, which is characterised by providing and timing the information in accordance with the patients' needs and encouraging them to talk about their feelings and concerns. ${ }^{1112}$

Whereas many studies regarding delivering difficult news focus on the content of the interaction, the context in which the news is shared is equally essential; for example, the organisation of setting and participants. ${ }^{13}$ The importance of face-to-face interactions between patients and physicians when delivering news of a prenatal diagnosis of Down syndrome (DS) was a central finding in the influential review by Skotko. ${ }^{14}$ 
Sometimes, however, this ideal cannot be met, and the difficult news of a prenatal diagnosis is delivered to the prospective parents by phone. ${ }^{4}$ This is also the case in the Central Denmark Region, where diagnostic results of invasive tests (chorionic villus sample (CVS) or amniocentesis) are routinely delivered by phone and have been for many years. This procedure was implemented to favour the majority of women, who receive a normal diagnostic result. They receive the good news of a normal result quickly and without the inconvenience of having to go to the hospital. However, for approximately $5 \%$ of couples, the result is abnormal ${ }^{15}$ and has the capacity to profoundly alter the pregnant couple's current life and desired future. Yet, we do not know if such a practice is indeed acceptable and/or appropriate from a patient's perspective and this knowledge is needed for the future development of patient-centred fetal medicine. To the best of our knowledge, no study has yet investigated how pregnant women and couples experience receiving a severe prenatal diagnosis over the phone.

Consequently, the aim of the present study was to investigate how the couples experienced receiving a prenatal diagnosis of DS by phone. The study included only couples who chose to terminate the pregnancy.

\section{METHODS}

\section{Design}

The present study is a substudy of a broader, explorative investigation of the experiences and decision-making processes of pregnant couples who chose to seek termination of pregnancy (TOP) following a prenatal diagnosis of DS. ${ }^{16}$ The study was set within an anthropological research paradigm ${ }^{17}{ }^{18}$ which aims to explore human experiences in relation to specific social and cultural contexts. The anthropological paradigm is characterised by an open-ended approach where data collection and interpretation is understood as an iterative-inductive process of cumulative development. The anthropological analysis is similar to other qualitative approaches (eg, grounded theory) but less prescriptive and more ready to adopt a mixture of relevant methodological and analytical concepts. ${ }^{19}$ The data in the present study were generated from explorative, semistructured interviews. ${ }^{20}$

\section{Study context}

Denmark has a tax-financed, free-of-charge healthcare system and comprehensive prenatal care is available to all pregnant women including a first trimester screening (FTS) programme for DS and other chromosomal abnormalities (see figure 1). The FTS uptake is high $(<90 \%)$ compared with other North European countries, ${ }^{21-23}$ and FTS is considered an integral part of prenatal care by most women. ${ }^{16} 24{ }^{25}$ Pregnant women who receive highrisk FTS results $(\geq 1: 300)$ are offered diagnostic testing which provides a definite result: either invasive testing in the form of CVS/amniocentesis or non-invasive prenatal testing (NIPT). A positive NIPT result is always confirmed by an invasive test. Usually, invasive test results are available within a week. When DS is diagnosed, termination rates are high $(>95 \%){ }^{15} 2627$ TOP is legal up to and including 12 gestational weeks and allowed on approval by a specialist board up to and including 22 gestational weeks.

\section{Study participants}

Participants were recruited from university and regional hospitals in the Central Denmark Region from February 2016 to July 2017. Couples who had received a prenatal diagnosis of DS and decided to seek TOP were identified and approached by a clinic nurse at the obstetric department where the TOP was undertaken (usually at time of discharge). The nurse provided oral and written information about the study. Upon verbal or written consent (depending on hospital regulation), the couple's details were forwarded to SL, who contacted the couple 4-7 weeks later and provided additional information and answered any questions. Of the 24 couples recruited, one woman could not be reached by phone, one cancelled the interview appointments repeatedly, and one underwent TOP because of intrauterine death (not own choice). Thus, a total of 21 couples participated in the study (see table 1 for the participants' characteristics). All women had opted for invasive tests, none had opted for NIPT. The indication for offering the diagnostic test was: a high-risk FTS result $(\mathrm{n}=19)$, a high-risk serum test (triple test) result $(\mathrm{n}=1)$, and short tubular bones detected at the second trimester scan $(n=1)$. Although the study design aimed at consecutive sampling, staff turnover and slips in recruitment procedures resulted in a convenience sample. However, recruitment continued until the researchers estimated that data saturation was met through a continuous evaluation of the adequacy and comprehensiveness of the data. ${ }^{28} 29$

\section{Data collection}

All couples were given the option of a joint interview or an individual interview with the woman only; 10 couples chose the latter, mostly citing conflicting schedules or the partner 'not being the talkative type' as reasons for this. By participant choice, all interviews were performed in the couples' homes. Prior to the interview, all participants were re-informed about study purpose, anonymity and their right to withdraw from the study at any time, and all participants signed a consent form. The qualitative interviews, which ranged from $45 \mathrm{~min}$ to $90 \mathrm{~min}$, were performed by SL, who is an experienced anthropologist. A semistructured interview guide with open-ended questions was used. The guide was designed to explore the couples' experiences of the diagnostic process, and the decision-making process regarding TOP. Specific and probing questions about the couples' experience of the phone call were also part of the guide. These questions formed the basis for the present analysis. In all interviews, participants were encouraged to speak freely about their experiences. During joint interviews, SL was careful to 


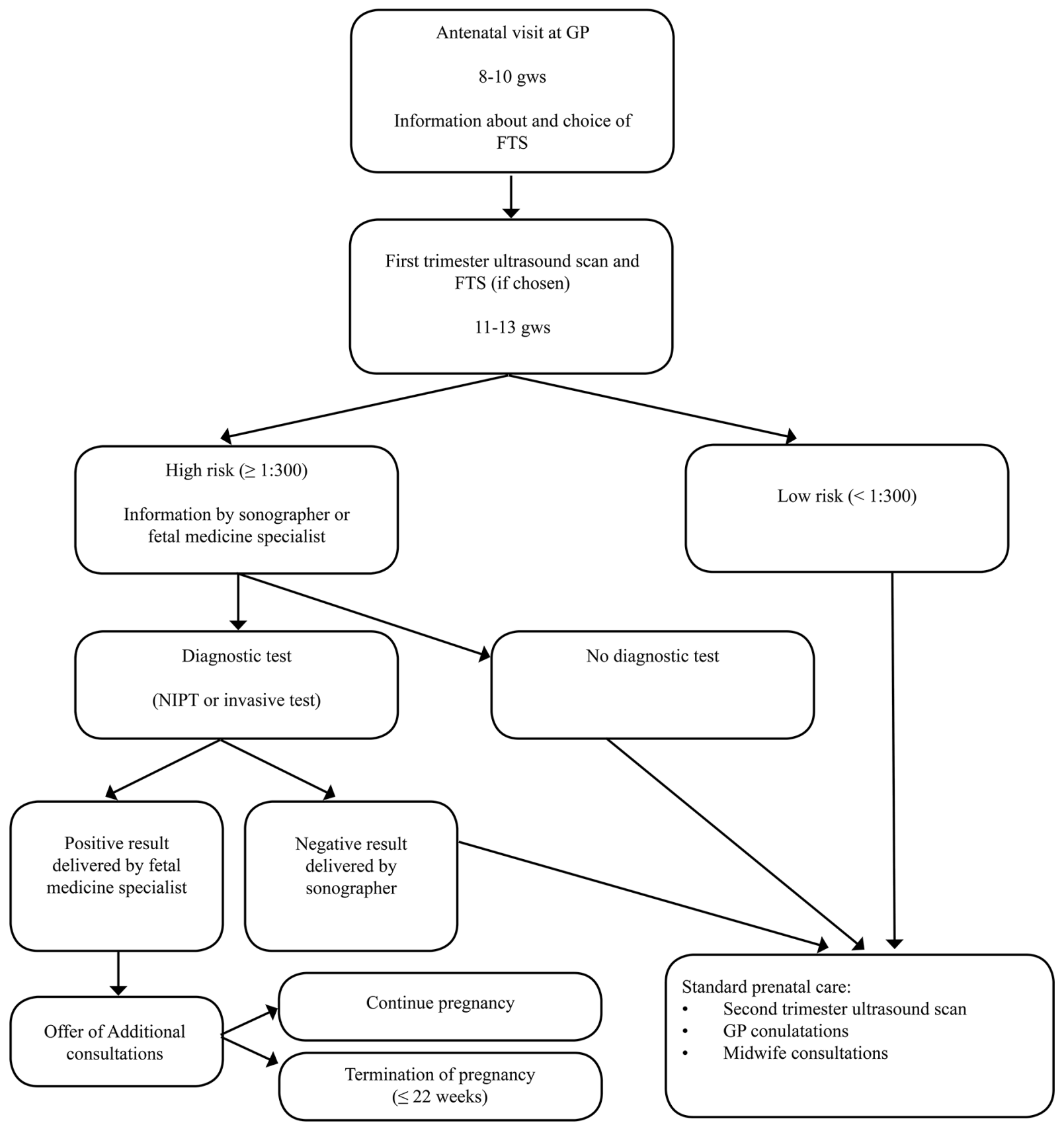

Figure 1 Flow chart of the Danish prenatal screening programme. FTS, first trimester screening; gws, gestational weeks; GP, general practitioner; NIPT, non-invasive prenatal test.

solicit the views of both parties. The participants were interviewed a median of 7 weeks after receiving the diagnosis. All interviews were digitally recorded, transcribed verbatim, and rendered anonymous, for example, through the use of pseudonyms.

\section{Data analysis}

Thematic analysis ${ }^{30}$ was used to identify patterns in the transcribed data. The material was continuously read and discussed by the authors during the interview period; however, for the final analysis, all material was thoroughly reread, and initial codes were generated. Three selected transcripts were all test-coded independently by SL, KC and ML, whereupon discrepancies in coding were discussed, leading to more detailed definitions of codes to minimise overlap in content. All interviews were then coded by SL and MRL using NVivo V.10 software (QSR International, Melbourne, Australia). The coded material was read and sorted into main and subthemes, which were discussed among all authors (see figure 2). Additionally, the themes were investigated in relation to the full data set looking for disconfirming evidence. ${ }^{31}$ Following this process, the final themes were defined and described.

\section{Patient involvement}

A study group was established consisting of qualitative researchers and physicians (fetal medicine, obstetrics, clinical genetics) with thorough experience with the 
Table 1 Participant characteristics

\begin{tabular}{|c|c|c|c|c|c|c|c|c|}
\hline & Participants & Age (years) & $\begin{array}{l}\text { Educational } \\
\text { level } \dagger\end{array}$ & Interview & Parity & FTS result & $\begin{array}{l}\text { Induced } \\
\text { abortion }\end{array}$ & $\begin{array}{l}\text { Weeks between } \\
\text { diagnosis and } \\
\text { interview }\end{array}$ \\
\hline \multirow[t]{2}{*}{1} & Anna* $^{*}$ & 39 & High & Woman only & 1 & NAł & Surgical & 8 \\
\hline & Hjalte & 41 & High & & & & & \\
\hline \multirow[t]{2}{*}{2} & Benedicte $^{\star}$ & 35 & Medium & Joint & - & $1: 62$ & Surgical & 6 \\
\hline & Phillip & 36 & Medium & & & & & \\
\hline \multirow[t]{2}{*}{3} & Cathrine $^{*}$ & 28 & High & Joint & 1 & $1: 10$ & Surgical & 9 \\
\hline & Mikkel & 29 & High & & & & & \\
\hline \multirow[t]{2}{*}{4} & Cecilie* & 37 & High & Joint & 1 & $1: 4$ & Surgical & 7 \\
\hline & Hans-Peter & 38 & Medium & & & & & \\
\hline \multirow[t]{2}{*}{5} & $\mathrm{Gry}^{*}$ & 37 & High & Woman only & 2 & $1: 4$ & Medical & 15 \\
\hline & Casper & 41 & Medium & & & & & \\
\hline \multirow[t]{2}{*}{6} & Jeanette* & 33 & High & Woman only & 2 & NAł & Surgical & 7 \\
\hline & Bo & 32 & Medium & & & & & \\
\hline \multirow[t]{2}{*}{7} & Karen* & 33 & High & Woman only & 1 & $1: 13$ & Medical & 6 \\
\hline & Martin & 35 & High & & & & & \\
\hline \multirow[t]{2}{*}{8} & Lise* & 35 & High & Joint & 1 & $1: 4$ & Medical & 6 \\
\hline & Jesper & 36 & Medium & & & & & \\
\hline \multirow[t]{2}{*}{9} & Louise* & 31 & Medium & Joint & - & $1: 254$ & Surgical & 8 \\
\hline & Tim & 27 & Medium & & & & & \\
\hline \multirow[t]{2}{*}{10} & Lene* & 39 & High & Woman only & 2 & $1: 20$ & Surgical & 12 \\
\hline & Steffen & 46 & High & & & & & \\
\hline \multirow[t]{2}{*}{11} & Maja* $^{\star}$ & 22 & Medium & Woman only & - & $1: 17$ & Surgical & 5 \\
\hline & Kristian & 25 & Medium & & & & & \\
\hline \multirow[t]{2}{*}{12} & $\mathrm{Mia}^{*}$ & 34 & High & Joint & 1 & $1: 300$ & Medical & 22 \\
\hline & Morten & 36 & High & & & & & \\
\hline \multirow[t]{2}{*}{13} & Mathilde ${ }^{*}$ & 44 & Low & Joint & 2 & $1: 4$ & Medical & 4 \\
\hline & Allan & 47 & Medium & & & & & \\
\hline \multirow[t]{2}{*}{14} & Michelle* $^{*}$ & 35 & High & Joint & 1 & $1: 157$ & Surgical & 6 \\
\hline & Markus & 37 & High & & & & & \\
\hline \multirow[t]{2}{*}{15} & $\mathrm{Mia}^{\star}$ & 36 & High & Woman only & - & $1: 2$ & Surgical & 6 \\
\hline & Marius & 33 & Low & & & & & \\
\hline \multirow[t]{2}{*}{16} & Randi* & 33 & High & Joint & 1 & $1: 2$ & Surgical & 9 \\
\hline & Mads & 32 & Medium & & & & & \\
\hline \multirow[t]{2}{*}{17} & Sofie* & 30 & Medium & Woman only & 2 & NA§ & Medical & 10 \\
\hline & Thor & 36 & Medium & & & & & \\
\hline \multirow[t]{2}{*}{18} & Signe* & 25 & Student & Joint & - & $1: 253$ & Medical & 5 \\
\hline & Klaus & 26 & Medium & & & & & \\
\hline \multirow[t]{2}{*}{19} & Sascha* & 40 & Medium & Joint & 2 & $1: 2$ & Surgical & 4 \\
\hline & Jens & 29 & Medium & & & & & \\
\hline \multirow[t]{2}{*}{20} & Sidsel $^{*}$ & 43 & High & Woman only & 2 & $1: 4$ & Surgical & 12 \\
\hline & Jonas & 38 & Medium & & & & & \\
\hline \multirow[t]{2}{*}{21} & Bertha* & 37 & Medium & Woman only & 2 & NAף & Medical & 8 \\
\hline & Theo & 40 & High & & & & & \\
\hline
\end{tabular}

*Women. All others are male partners.

†Using the International Standard Classification of Education from Statistics Denmark (ISCED), educational level was grouped in three categories; low (1-10 years), medium (11-14 years) and high (>15 years).

¥Numerical risk figure not provided to couple at FTS.

§Detected at second trimester scan.

ףldentified by triple test.

FTS, first trimester screening; NA, not available. 


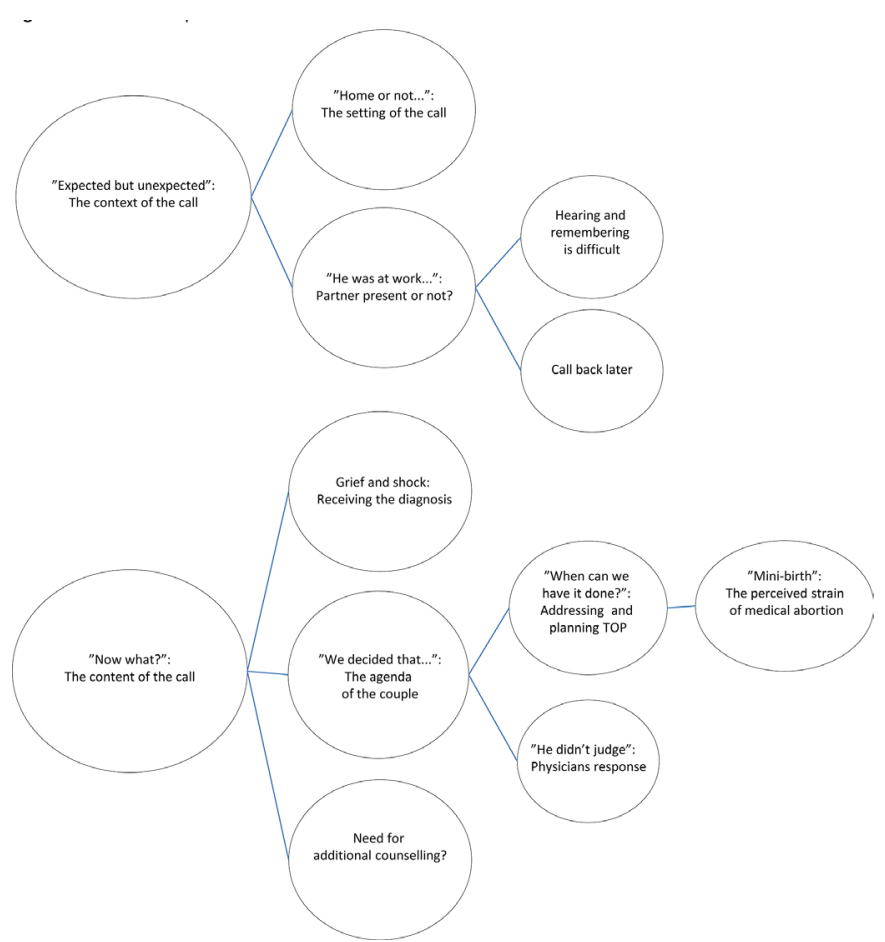

Figure 2 Thematic map. TOP, termination of pregnancy.

patient group; however, patients were not directly involved in designing the study. During recruitment and data collection, participants were encouraged to provide feedback on recruitment procedures/interview experience, and initial findings were often informally discussed by SL and the couples after each interview. However, patients were not directly involved in the actual data analysis. The study was discussed with the Danish National Association for Down Syndrome, who also gave feedback on preliminary results. Finally, the results were disseminated to all participants who agreed to receive such information. All feedback from participants was positive.

\section{RESULTS}

Generally, the couples agreed that receiving the diagnostic result by phone was an acceptable and reasonable solution. When explicitly asked about their overall thoughts about the call, twenty couples expressed what we have categorised as high or adequate satisfaction with the total experience, whereas one woman was dissatisfied. In her case, the calling physician had abruptly ended the call because of an emergency at the obstetric department. Despite the general acceptance of the phone call as a reasonable means of receiving the diagnosis and the overall satisfaction with the call and the calling physician, the analysis revealed a number of areas where the situation was nevertheless less than optimal for the couples. These areas will appear as part of the main themes: (1) 'Expected, but unexpected' and (2) 'Now what?' that are presented in more detail below.

\section{Expected, but unexpected. The context of the call}

This theme included the couples' experience of the timing and setting of the call, as well as their reflections on the people present during and immediately after the conversation.

When asked about the setting in which they received the call, the women reported being at home $(n=10)$, at work $(n=6)$, in a car $(n=4)$ or at the grocery store $(n=1)$. The majority received the call at least 1 day earlier than expected. While they appreciated receiving the result as fast as possible to end the difficult waiting time, the unexpected timing of the call caused surprise and confusion. Many found themselves in less than ideal circumstances for receiving difficult news, but did not think to interrupt or postpone the call. This led to some women finding themselves in a company vehicle or a vacant meeting room when learning the diagnostic result:

When the doctor asked if I was free to talk, I stepped into one of our meeting rooms and said 'yes' and she just said: 'Your child has Down syndrome'. And I just burst out: "Are we really the 1 in 1:254?!!" And when she said 'I'm sorry'. Oh, it was completely surreal. I was in a complete state of shock (crying). (Louise)

Women who received the call while at work reported breaking down in front of co-workers. Often, co-workers were unaware of the pregnancy and the women had not initially intended to share this personal situation of prenatal testing with them. All women reported receiving understanding and support from co-workers, such as hugs, getting the day off, or getting a ride home, but all considered the situation inappropriate.

Irrespective of setting, the majority of the women received the news without their partner present. Receiving diagnosis without the partner present was experienced as less than optimal. First, the news caused intense grief and sadness and thus a need for comfort and support, and second, the stress of the situation caused an inability to hear all the details of the information provided by the physician:

Honestly, I don't remember all the details from that conversation. And the doctor never asked if I was alone or anything - I think an extra set of ears is a good thing in a situation like that. (Karen)

I called Klaus (boyfriend), but I don't know if you (looking at Klaus) could even understand a word I was saying through all the tears? (Signe)

All women in the material reported feeling shock, sadness and confusion when learning the result. In this state, many had difficulties remembering and recounting the information provided by the physician. Being responsible for passing the information on to their partner was a challenge for some of the women, as delivering difficult news can be difficult per se, and the partner sometimes asked for information that the woman had either forgotten or failed to ask the physician about. 
Three of the women who had not been with their partners at the time of the call were asked by the physician to summon their partner and call the physician back to get the result:

I was in the car with my mum and my daughter when the doctor called. He said, 'I'm calling about the results, and I think your husband should be present when I give them to you.' And I was like, 'Ok, you're making me nervous now,' but he didn't respond to that, he was very neutral. Of course, I suspected that something was wrong because otherwise he would just have said, 'No need to worry!' (Michelle)

These women reported feeling worried and suspicious of a DS result while preparing for the return call. However, they also appreciated this mode of feedback as it gave them time to prepare for difficult news and allowed them to hear the news together with their partner. With this approach, the physician gave the couple the opportunity to decide and organise the setting and participants of the conversation:

Actually, I really appreciate that we got the opportunity to get the news together. That I didn't have to pass it on to Markus (husband) and he would be, like, what? Did you get the facts right? Did you ask about this and that? This way, we heard the same thing, we were completely equal in it. (Michelle)

Because of extreme stress, one woman arranged with the hospital to call at a set day and time. The hospital was not to call her even if the result came earlier. This opportunity to decide the timing, setting and participants of the call was described by the couple as an ideal situation, and requested by several other participants.

\section{Now what? The content of the call}

This theme included the couples' recollection and assessment of the content of the phone call, including what was communicated and how.

When answering the phone, most women suspected the diagnosis during the first few seconds of the call:

The first thing she (the physician) asked was 'Where are you?' - so then I knew. (Cecilie)

Just from the tone in their voice, you can tell it's not gonna be good news. (Gry)

Some physicians initiated the delivery with an empathetic 'I am sorry to tell you this...,' whereas others were more straightforward with a 'I have your test result here and it shows that....' Although both types of delivery were appreciated by the couples, a few noted that the empathetic approach would be inappropriate for couples who considered continuing the pregnancy.

In most cases, the physician presented the diagnosis and then enquired about the woman/couple's considerations regarding the diagnosis:
And then he said that we had an important decision to make, if we hadn't made one already? So I told him that we wanted to terminate. We have two young children and I just couldn't see how we could make that work. (Jeanette)

Inviting the women to share their thoughts and decisions early in the conversation was much appreciated. This allowed the conversation to go in a direction relevant to the needs and concerns of the couple. For the majority of couples, the decision to seek TOP in the case of a diagnosis of DS had been made prior to receiving the call. These couples appreciated that their decision to seek TOP was quickly brought to the fore and that the physician did not question it or require justification:

And it meant a lot to me that she didn't doubt my decision or lecture me on ethics or something. That would have been too much for me. But she was very straight forward and just followed my initiative. (Anna)

And when I started to explain, (the physician) was like 'You don't need to explain yourselves. I understand why this is your choice.' [.] It took some weight off my shoulders...that he didn't judge. (Klaus)

The majority of couples valued not being introduced to extensive information about DS or living with a child with DS, but still appreciated when physicians mentioned that continuation of pregnancy was also an option:

Actually, the doctor kept the decision open for quite a while. He was like this and that is also an option and I was a little puzzled by that. Because...we were just so certain about our decision. But I guess it's a good thing, if people have doubts. (Lene)

For the 18 couples who were already settled on TOP prior to receiving the actual diagnosis, the pending procedure was their main concern during the conversation. They appreciated that the physicians presented different options (medical/surgical) and addressed a (near) potential date and time for the TOP procedure. Several couples expressed relief that the physicians made the practical TOP arrangements for them, including arrangements with the regional council, which must approve all TOP at $>12$ gestational weeks. This allowed the couple to focus on their grief and the personal arrangements that had to be made (eg, get time off work, arrange baby-sitting, inform prospective grandparents).

Five women reported feeling rushed after the phone call. They were all close to $13+6$ gestational weeks, the cut-off for surgical abortion in Denmark. In their cases, the physician had addressed the approaching cut-off in the conversation; indeed, some physicians had already initiated a surgical TOP appointment:

When we called them back to confirm that we wanted to terminate, the doctor said: "Please don't think that I am trying to rush you or something, but I already 
booked an appointment for you tomorrow. I can unbook it if you want, but since you are this far along, you have to get the surgical abortion tomorrow.' And I was like, thank you! I want full anaesthesia, total blackout. No mini-birth for me, thank you. (Michelle)

Prior to TOP, none of the women in this study had actual experience with second trimester medical abortion (though two women had previously experienced second trimester spontaneous abortion). Nevertheless, the analysis showed how medical abortion at $\geq 14$ gestational weeks (by several women termed 'mini-birth') was generally considered to be more physically and emotionally demanding than surgical abortion, and thus something to be preferably avoided. Though feeling rushed, the women appreciated that the physicians had brought up the issue, thereby allowing them to have a choice and make their own decision. All five women chose surgical abortion.

All couples reported knowing the next step when the phone call ended. Many were offered a follow-up phone call or the opportunity to call the physician back, which was highly appreciated as a gesture of the physician's involvement in the situation, and as an opportunity to digest the answer. Arrangements for further face-to-face information or counselling (same or following day) were made with 11 couples. Whether the couples who did not have follow-up meetings were offered such meetings remains unclear; however, none of the participants in this group reported missing such a meeting.

\section{DISCUSSION}

\section{Main findings}

To the best of our knowledge, this is the first study to focus explicitly on pregnant couples' experiences of receiving a prenatal diagnosis of DS over the phone. Overall, the couples considered the phone call an appropriate mode of communicating abnormal results. However, the analysis also revealed a number of less-than-optimal features-particularly related to the context of the call ('Expected, but unexpected' theme). The majority of couples received the call earlier than expected, which was appreciated; however, this was inconvenient for some. Half of the women were not at home when receiving the call, and the majority did not have their partner present. Therefore, the women were initially alone when having to deal with their grief, and additionally, they were responsible for informing their partner of the result. During the phone call ('Now what?' theme), the physician's tone of voice and way of initiating the conversation served as a warning shot for most women. The physicians were quick to present the result and to enquire about their considerations, which supported a patient-centred agenda. The majority of the couples had already decided to seek TOP, and thus the conversation centred on TOP-related questions and arrangements. Half of the couples received additional counselling, while the remaining couples went straight to TOP.

\section{Interpretation}

A central finding of the present study concerns the content of the conversations. In most cases, the physician took a patient-centred approach in the sense that she/ he focused on the responses and emotions of the couple and on the aspects of the diagnosis that were important to them. This approach of seeking direction from patients revealed that many couples' major concerns and information needs revolved around TOP. This finding adds a new perspective to other studies reporting that after a prenatal diagnosis, parents request detailed and up-todate information about the diagnosis and prognosis. ${ }^{314} 32$ In the present study that was not the case. One explanation for this may be that the majority of couples in this sample had already made the decision to seek TOP prior to receiving the diagnosis. Certainly, substantial and reliable information-from several sources-is important when couples are still in the decision-making process. However, for couples who express a conclusive personal decision, providing thorough information about DS at the time of diagnosis may be experienced as inappropriate and as a lack of support. To prevent such situations, information about DS could be provided earlier in the diagnostic process. Earlier information about DS could also prevent situations, where a physician may suspect a pregnant couple of making a rushed TOP decision as a coping mechanism in a difficult and unpleasant situation. To counter impulsive moves and promote informed decision-making, physicians could encourage pregnant couples to take some postdiagnosis time together to consider and consolidate the decision-even in cases of a conclusive personal decision. ${ }^{33}$

Another central finding of the present study is the importance of the context in which the phone call takes place; of being able to answer the phone call in an appropriate setting and with participants of one's own choice. In line with other studies, ${ }^{34-36}$ our study shows how pregnancy is a joint and collaborative project for many couples. Informing the woman without her partner present disregards the couples' joint investment in the pregnancy by putting the woman in charge of talking to the physician, and passing on the information. Based on the results, we suggest that the calling physician has different ways of providing the couple with this opportunity. The calling physician can either choose not to reveal the diagnosis until the couple is together in an appropriate setting, or arrange to call the couple at a specific pre-established time and stick to the agreement, even if the results are available earlier than expected. However, our results point to how such an arrangement might be problematic in situations where the gestational age is approaching the cut-off for surgical abortion. The women in the present study felt rushed but appreciated the opportunity to make their own decision which is in line with other studies showing higher satisfaction among women, who have the 
option of choosing the mode of TOP. ${ }^{37-40}$ The physician may address these issues in connection with the invasive procedure and let the couple choose how they prefer to receive the answer, including an early answer.

\section{Strengths and limitations of the study}

Some key strengths of this study are the relatively large sample and that we were able to continue inclusion until adequate data material was obtained. ${ }^{28}$ In addition, participants were interviewed shortly after receiving the diagnosis, which limits the risk of recall bias. Furthermore, all interviews were conducted by an anthropologist with substantial, qualitative research experience within the fields of pregnancy and prenatal screening. This is important as qualitative, empirical data are co-constructed between researcher and participant and a skilled and experienced interviewer may elicit more nuanced responses from participants. ${ }^{18}{ }^{28}$ Finally, researcher triangulation in all processes of analysis supported a critical and reflexive analytical process. However, when assessing this study, some potential limitations should also be taken into account. First, the data for this analysis are based on couples' recollections of the conversation, and thus their personal narratives of receiving a prenatal diagnosis of DS by phone; therefore, they do not represent a report of what was actually said. Second, the sample only includes couples who chose to seek TOP. In Denmark, only one to nine couples annually choose to continue a pregnancy following a prenatal diagnosis of DS. ${ }^{27}$ This group may have a different experience of receiving a diagnosis by phone, as studies have shown this group to report negative experiences and lack of up-to-date information in the interactions with healthcare professionals. ${ }^{3} 4142$ This will be examined in a future study of couples who continue the pregnancy after a diagnosis of DS. And third, due to participant choice, 10 interviews included only the woman. It is a study limitation that these interviews only include the woman's perception of her partner's reaction and not his actual perspective; however, a comparison showed no major difference in the experiences and concerns brought forward in the individual and joint interviews. Finally, qualitative results must always be understood within their specific context-in this case, the comprehensive and free-for-all prenatal screening programme in Denmark, in which prenatal screening for DS is considered routine by many, and termination rates are high. ${ }^{15262743}$ This may result in more Danish women having decided to seek TOP prior to participating in screening, which again may affect the content of and satisfaction with the diagnostic call. The results of this study are not generalisable in the quantitative sense of the concept; however, they are not intended to be. Rather, our results may provide insights that are useful for researchers in related fields and for clinicians in similar contexts.

\section{Future research}

This study is restricted to providing the couple's experiences of receiving a DS diagnosis over the phone. It would be equally important to conduct a study of the experience of the calling physician and the perspectives and concerns that shape physician's approach to the conversation. Interestingly, in the related field of prenatal genetics there is a significant amount of scientific literature on clinician's perspectives, for example, considerations about how to best inform about testing options and convey results, ${ }^{44-46}$ or how to involve patients in decision-making. ${ }^{48}$ With some exceptions ${ }^{249}$, such a tradition of investigating the professional's views is currently lacking within fetal medicine and could be investigated further.

\section{CONCLUSIONS}

When agreed on in advance, a prenatal diagnosis of DS can be appropriately delivered by phone. The calling physician should consider how to give couples the opportunity to be together and in an appropriate setting when learning the result. After disclosure of the diagnosis, the physician should focus on aspects of the diagnosis that are important to the couple, while being sensitive to additional information needs. Also, the physician could allow time for reflection and consolidation in order to avoid impulsive decision-making. To support good communication of a potential diagnosis of DS, physicians should address in advance how the result should best be delivered in accordance with the needs and requests of the couples.

Acknowledgements The authors thank all the women and partners who took time to participate in interviews and openly shared their experiences and views with us. The authors also thank the midwives, nurses and physicians from Aarhus University Hospital and from the Regional Hospitals in Central Denmark Region, who recruited participants for this study.

Contributors SL, LH and OBP designed the study. SL did the data collection. The process of data analysis was conducted by $\mathrm{SL}, \mathrm{KC}$ and $\mathrm{ML}$ in close collaboration with IV, LH, CPN and OBP. All authors contributed to the writing and approved the final manuscript.

Funding The research was supported by the Health Research Fund of Central Denmark Region (Grant R5-A186) and by the Novo Nordisk Foundation (Grant NNF160C0018772).

Competing interests None declared.

Patient consent for publication Not required.

Ethics approval The study was approved by the Danish Data Protection Agency (J. No. 1-16-02-196-16). According to Danish law, approval by the National Committee on Health Research Ethics was not required as no biomedical intervention was performed (www.nvk.dk). However, the study was performed in accordance with the code of ethics for qualitative research as formulated by the American Anthropological Association (www.ethics.americananthro.org). The participants received oral and written study information about the aim and methods of the study; and informed, written consent was obtained prior to interviews. The participants were informed that consent could be withdrawn at any time.

Provenance and peer review Not commissioned; externally peer reviewed.

Data sharing statement All transcripts are available in Danish and may be obtained from the first author upon reasonable request. Prerequisites are that a research protocol is submitted and approved. Apart from the transcripts, no additional data are available.

Open access This is an open access article distributed in accordance with the Creative Commons Attribution Non Commercial (CC BY-NC 4.0) license, which permits others to distribute, remix, adapt, build upon this work non-commercially, and license their derivative works on different terms, provided the original work is 
properly cited, appropriate credit is given, any changes made indicated, and the use is non-commercial. See: http://creativecommons.org/licenses/by-nc/4.0/.

\section{REFERENCES}

1. Pilnick A, Zayts O. Advice, authority and autonomy in shared decision-making in antenatal screening: the importance of context. Sociol Health IIIn 2016;38:343-59.

2. Edvardsson $\mathrm{K}$, Small $\mathrm{R}$, Persson $\mathrm{M}$, et al. 'Ultrasound is an invaluable third eye, but it can't see everything': a qualitative study with obstetricians in Australia. BMC Pregnancy Childbirth 2014;14:363.

3. Lou S, Jensen LG, Petersen OB, et al. Parental response to severe or lethal prenatal diagnosis: a systematic review of qualitative studies. Prenat Diagn 2017;37:731-43.

4. Pitt P, McClaren BJ, Hodgson J. Embodied experiences of prenata diagnosis of fetal abnormality and pregnancy termination. Reprod Health Matters 2016;24:168-77.

5. Hunt K, France E, Ziebland S, et al. 'My brain couldn't move from planning a birth to planning a funeral': a qualitative study of parents' experiences of decisions after ending a pregnancy for fetal abnormality. Int J Nurs Stud 2009;46:1111-21.

6. Monden KR, Gentry L, Cox TR. Delivering bad news to patients. Proc 2016;29:101-2.

7. Sparks L, Villagran MM, Parker-Raley J, et al. A Patient-centered approach to breaking bad news: communication guidelines for health care providers. J of Applied Communication Research 2007;35:177-96.

8. Burgers C, Beukeboom CJ, Sparks L. How the doc should (not) talk: when breaking bad news with negations influences patients immediate responses and medical adherence intentions. Patient Educ Couns 2012;89:267-73.

9. Kleinert HL, Lunney CA, Campbell L, et al. Improving residents understanding of issues, comfort levels, and patient needs regarding screening for and diagnosing down syndrome. Am J Obstet Gynecol 2009;201:328.e1-6.

10. Bryant LD, Puri SC, Dix L, et al. Tell it Right, Start it Right: An evaluation of training for health professionals about Down syndrome. Br J Midwifery 2016;24:110-7.

11. Harrison ME, Walling A. What do we know about giving bad news? A review. Clin Pediatr 2010;49:619-26.

12. Schmid Mast M, Kindlimann A, Langewitz W. Recipients' perspective on breaking bad news: how you put it really makes a difference. Patient Educ Couns 2005;58:244-51.

13. Ptacek JT, Eberhardt TL. Breaking bad news. a review of the literature. JAMA 1996:276:496-502.

14. Skotko BG, Kishnani PS, Capone GT. Prenatal diagnosis of Down syndrome: how best to deliver the news. Am J Med Genet $A$ 2009;149A:2361-7.

15. Ekelund CK, Jørgensen FS, Petersen OB, et al. Impact of a new national screening policy for down's syndrome in denmark: population based cohort study. BMJ 2008;337:a2547

16. Lou S, Dahl K, Risør MB, et al. [A qualitative study of pregnant women's choice of nuchal translucency measurement]. Ugesk Laeger 2007;169:914-8

17. Carter SM, Little M. Justifying knowledge, justifying method, taking action: epistemologies, methodologies, and methods in qualitative research. Qual Health Res 2007;17:1316-28.

18. Hammersley M, Atkinson P. Ethnography: principles in practiceed. London: Routledge, 2007.

19. O'Reilly K. Ethnographic methods. London: Routledge, 2012

20. Kvale S, Brinkmann S. Interviews: learning the craft of qualitative research interviewing. Los Angeles: Sage Publications, 2009.

21. Regionernes kliniske kvalitetsudviklingsprogram. Dansk Føtalmedicinsk database. National årsrapport 2016. [Danish fetal medicine database. Annual report]. (In Danish. No abstract available) Copenhagen: Regionernes kliniske kvalitetsudviklingsprogram. 2016 http://www.dfms.dk/images/foetodatabase/Arsrapport_FOTO_2016_ final_anonymiseret.pdf (Accessed August 14 2018).

22. Crombag NM, Vellinga YE, Kluijfhout SA, et al. Explaining variation in down's syndrome screening uptake: comparing the netherlands with england and denmark using documentary analysis and expert stakeholder interviews. BMC Health Serv Res 2014;14:437.

23. Alderdice F, McNeill J, Rowe R, et al. Inequalities in the reported offe and uptake of antenatal screening. Public Health 2008;122:42-52.

24. Schwennesen N, Koch L. Representing and intervening: 'doing' good care in first trimester prenatal knowledge production and decisionmaking. Sociol Health IIIn 2012;34:283-98.
25. Bangsgaard L, Tabor A. Do pregnant women and their partners make an informed choice about first trimester risk assessment for Down syndrome, and are they satisfied with the choice? Prenat Diagn 2013;33:146-52.

26. Petersen OB, Vogel I, Ekelund C, et al. Potential diagnostic consequences of applying non-invasive prenatal testing: populationbased study from a country with existing first-trimester screening. Ultrasound Obstet Gynecol 2014;43:265-71.

27. Lou S, Petersen OB, Jørgensen FS, et al. National screening guidelines and developments in prenatal diagnoses and live births of Down syndrome in 1973-2016 in Denmark. Acta Obstet Gynecol Scand 2018;97:195-203.

28. Morse JM. The significance of saturation. Qual Health Res 1995;5:147-9.

29. Malterud K, Siersma VD, Guassora AD. Sample size in qualitative interview studies: guided by information power. Qual Health Res 2015;26:1753-60.

30. Braun V, Clarke V. Using thematic analysis in psychology. Qual Res Psychol 2006;3:77-101.

31. Patton MQ. Qualitative research and evaluation methods. Newbury Park: Sage, 2002.

32. Carlsson T, Bergman G, Melander Marttala U, et al. Information following a diagnosis of congenital heart defect: experiences among parents to prenatally diagnosed children. PLoS One 2015;10:e0117995

33. Lou S, Carstensen K, Petersen OB, et al. Termination of pregnancy following a prenatal diagnosis of down syndrome: a qualitative study of the decision-making process of pregnant couples. Acta Obstet Gynecol Scand 2018;97:1228-36.

34. Werner-Lin A, McCoyd JL, Bernhardt BA. Balancing genetics (science) and counseling (art) in prenatal chromosomal microarray testing. J Genet Couns 2016;25:855-67.

35. Carroll FE, Owen-Smith $A$, Shaw $A$, et al. A qualitative investigation of the decision-making process of couples considering prenatal screening for down syndrome. Prenat Diagn 2012;32:57-63.

36. Draper J. 'It was a real good show': the ultrasound scan, fathers and the power of visual knowledge. Sociology of Health \&amp; IIIness 2002;24:771-95

37. Lou S, Nielsen CP, Hvidman L, et al. Coping with worry while waiting for diagnostic results: a qualitative study of the experiences of pregnant couples following a high-risk prenatal screening result. BMC Pregnancy Childbirth 2016;16:321.

38. Rørbye C, Nørgaard M, Nilas L. Medical versus surgical abortion: comparing satisfaction and potential confounders in a partly randomized study. Hum Reprod 2005;20:834-8.

39. Kelly T, Suddes J, Howel D, et al. Comparing medical versus surgica termination of pregnancy at 13-20 weeks of gestation: a randomised controlled trial. BJOG 2010;117:1512-20.

40. Kerns JL, Light A, Dalton V, et al. Decision satisfaction among women choosing a method of pregnancy termination in the setting of fetal anomalies and other pregnancy complications: a qualitative study. Patient Educ Couns 2018;101:1859-64.

41. Kerns JL, Mengesha B, McNamara BC, et al. Effect of counseling quality on anxiety, grief, and coping after second-trimester abortion for pregnancy complications. Contraception 2018;97:520-3.

42. Goff BSN, Springer N, Foote LC, et al. Receiving the initial Down syndrome diagnosis: a comparison of prenatal and postnatal parent group experiences. Intellect Dev Disabil 2013;51:446-57.

43. Skotko BG. Prenatally diagnosed down syndrome: mothers who continued their pregnancies evaluate their health care providers. Am J Obstet Gynecol 2005;192:670-7.

44. Agatisa PK, Mercer MB, Coleridge M, et al. Genetic counselors perspectives about cell-free DNA: experiences, challenges, and expectations for obstetricians. J Genet Couns 2018;27:1374-85.

45. Bernhardt BA, Kellom K, Barbarese A, et al. An exploration of genetic counselors' needs and experiences with prenatal chromosomal microarray testing. J Genet Couns 2014:23:938-47.

46. Walser SA, Kellom KS, Palmer SC, et al. Comparing genetic counselor's and patient's perceptions of needs in prenatal chromosomal microarray testing. Prenat Diagn 2015;35:870-8.

47. Lafans RS, Veach PM, LeRoy BS. Genetic counselors' experiences with paternal involvement in prenatal genetic counseling sessions: an exploratory investigation. J Genet Couns 2003;12:219-42.

48. Graziani RNA, Nemzer L, Kerns J. The experience of genetic counselors working with patients facing the decision of pregnancy termination after 24 weeks gestation. J Genet Couns 2018;27:626-34.

49. Tucker Edmonds B, Krasny S, Srinivas S, et al. Obstetric decisionmaking and counseling at the limits of viability. Am J Obstet Gynecol 2012;206:248.e1-5. 